\section{PSORIASIS REMOVED BY EXFOLIATIVE} DERMATITIS.

\section{To the Editor of THE LANCET.}

SIR,-An interesting book has yet to be written on the partnerships and antagonisms of diseases, which are both diverse and curious. A.B., aged 23, had had psoriasis since 6 years of age, in patches on the arms, abdomen, thighs, and back. On May 5th an attack of acute exfoliative dermatitis started up, which he attributes to partaking of oysters. It affected his whole cutaneous surface, including the hairy scalp. His face, chest, abdomen, arms, and thighs were a mass of white papery scales overlying a red, thickened cutis. His nails were deeply grooved from the arsenic which had been often administered for his psoriasis. I did not see him until May 25th, when his state was as described above. There was some pyrexia: I put him on milk diet, administered sulphocarbolates internally, and applied an ointment of zinc lanoline and ichthyol 10 per cent. Calomel as an aperient and antiseptic was also given freely, and Dover's powder to procure sleep. Glycerine baths were tried later. He steadily improved. On June 30 th he came to see me, and his skin was smooth and clean everywhere and all traces of psoriasis had disappeared.

I ám, Sir, yours faithfully,

EDWaRd C. B. IBotson, M.D. Lond.

August 10th, 1914

\section{THE WORKING OF THE NATIONAL INSURANCE ACT IN GREAT YARMOUTH. \\ To the Editor of THE LANCET.}

SIR,-As all our minds are engrossed now with more serious matters I do not propose to make any detailed reply to what I consider Dr. Blake's in. accuracies. I think the correspondence that has already appeared will explain quite clearly to the readers of THE LANCET how bitterly the nonpanel men have reason to feel aggrieved by the action of their brethren, with whom previously they were so much in accord.

I am, Sir, yours faithfully,

RAYMOND HenRY SHatw.

Great Yarmouth, August 11th, 1914.

\section{IRRADIATION AND PRECOCIOUS REACTIONS \\ To the Editor of THE LANCET.}

SIR,-Marquès, in the Archives d'Electricite Médicale for August, 1912, stated that irradiation in the region of the salivary glands was followed in a very large number of cases by a marked reaction, one of his colleagues putiing it at as many as 25 per cent. He attributed this result to the effect produced on the salivary glands themselves, and described the clinical signs as those of acute inflam. mation, commencing a few hours after a very feeble dose (the exact amount was not stated), and subsiding in about 48 hours. The same reaction recurred on repeating the dose a fortnight later.

I have recently had a similar experience, follow. ing a one-half pastille dose administered to the beard area which I should like to bring before your readers. The ordinary signs of acute inflammation began to make their appearance a few hours later; there was no salivation, the salivary glands themselves did not appear to be specially involved, the appearances being more those of a general cellulitis of the irradiated area. The reaction subsided rapidly in about 48 hours, as in the cases described by Marquès. At a later date a second dose of onehalf pastille dose, measured above a filter of $0.5 \mathrm{~mm}$. $\mathrm{Al}$, resulted in a recurrence of the reaction, though slightly less severe in nature. The case was one of coccigenic sycosis of a stubborn type. I was led by these comments of Marquès to produce epilation by divided doses, and judging by the extraordinary reaction produced in this case by a half dose it would seem to be a wise precaution to adopt. In the case recorded by Marquès the patient was also a male, and the irradiation had been undertaken for a slight adenitis in the submaxillary region.

I am, Sir, yours faithfully,

FREDK. HARIVOOd-HARDMAN,

Eastbourne, August 6th, 1914.

\section{INFANT FEEDING}

\section{To the Editor of THE LANCET.}

SIR,-There is an important mass of citizens, the youngest of all, whose food-supply needs careful safeguarding at the present time. The test of a nation's survival is prolonged many years beyond the time at which the fitness of its soldiers and sailors is at stake.

There is need, therefore, that views on infant feeding, seldom very rarely regarded, should now receive special attention, and the occasion would seem to call for authoritative pronouncement which might be resented in a moment of less urgency. And it must be urged that breast feeding, properly carried out, is the only means that can be relied on effectually to safeguard the welfare of infants. Further, breast feeding is perfectly easy of successful accomplishment in nearly 100 per cent. of cases where children are born at or about the full term of gestation. This is a physiological rule which should scarcely need emphasis. But its obvious nature is frequently overlooked by those who cannot lay aside prejudices in favour of one $\mathrm{or}^{2}$ other of the methods by which it can be replaced, and who fail to regard parturition as merely a step in the reproductive cycle. Lactation may be watched in process of preparation throughout pregnancy. There is no hesitation in regarding it as a sign of great importance in the diagnosis, and its establishment coincides with the birth of the child with punctual precision. Its early cessation is due in the great majority of cases to mismanagement, and is so frequent as to have bred a tendency among members of the public, and even well-educated members, to disregard its supreme importance to infant welfare. The outpatient departments of our children's hospitals are largely concerned with trying to remedy the effects of this faulty performance, and this is no moment to swell the number of attendances.

Fortunately, the correction of the most prevalent errors in the conduct of breast feeding consists in measures which are extremely simple, and which lighten what is considered to be its chief burden. There can be no question that too frequent suckling is the commonest and most invalidating of all mistakes. It is responsible for impoverishment of the quality and quantity of the milk, dissatisfaction in the infant, and physical fatigue in the mother. The lack of any general agreement on the number of feeds in 24 hours which is best suited to the physiology of lactation and the digestive powers of young infants exists chiefly because these two aspects of the problem are seldom considered in conjunction with one another, with the result that commonly both functions are grossly overtaxed. 